\title{
Legislation
}

\section{The Assisted Reproduction Bill 2017: an analysis of proposals to regulate surrogacy in Ireland}

\author{
LYDIA BRACKEN \\ School of Law, University of Limerick
}

\begin{abstract}
Introduction
$\mathrm{T}$ the General Scheme of the Assisted Human Reproduction Bill 2017 was approved for drafting by the Irish government on the 3 October 2017. When published, most media outlets focused on the Minister for Health's announcement concerning state funding for in vitro fertilisation (IVF) treatment, with little commentary on the substantive provisions of the Bill. ${ }^{1}$ This is perhaps surprising given that this Bill has been 'imminent' since February $2015^{2}$ and has been eagerly awaited by all stakeholders for some years. The Bill proposes to further regulate the area of assisted human reproduction (AHR), essentially filling in the gaps of the regulation created (but not yet commenced) by the Children and Family Relationships Act 2015. The Bill provides for:

1 the regulation of assisted human reproduction;

2 gamete and embryo donation for use in assisted human reproduction treatment and research;

3 posthumous assisted reproduction involving the gametes or embryos of a deceased person under certain conditions;

4 pre-implantation genetic diagnosis and sex selection;

5 surrogacy;

6 embryo and stem cell research; and

7 the creation of a new Assisted Human Reproduction Regulatory Authority.
\end{abstract}

This article examines the proposals for surrogacy that are set out in the General Scheme. It argues that these proposals are unnecessarily complicated and that the delayed model of parentage that is proposed would not be an adequate approach to regulation in Ireland. It is argued that Ireland should instead adopt a pre-conception model of parentage in surrogacy in order to better protect the interests of all those involved in the surrogacy process.

1 S Bardon, 'Government to Pay for Couples to have IVF Treatment' Irish Times (Dublin, 3 October 2017); 'Cabinet Approves Legislation for IVF Financial Aid' RTENews.ie (3 October 2017) <www.rte.ie/news/2017/1003/909224-cabinet_maternity/>.

2 Department of Health, 'Govt to Legislate for Assisted Human Reproduction and Associated Research (Press release, Department of Health 25 February 2015) < http://health.gov.ie/blog/press-release/govt-to-legislatefor-assisted-human-reproduction-associated-research $>$. 


\section{Surrogacy in Ireland}

Surrogacy is a process whereby a person agrees to carry a child on behalf of another person or couple. It is a process that raises complex legal, ethical and moral considerations about a range of issues such as the potential commodification of children; the psychological development of children born through surrogacy; and the perceived exploitation of women who act as surrogates. There is no consensus on these questions and as a result countries adopt varying approaches to the regulation of surrogacy. In some countries, surrogacy is permitted and fully regulated, ${ }^{3}$ in other jurisdictions surrogacy is legal but there is no regulation, ${ }^{4}$ while in other countries surrogacy is prohibited completely. ${ }^{5}$ Ireland currently falls into the middle category: tolerant but (arguably) not accommodating (due to the lack of regulation). The absence of legislation to specifically address surrogacy gives rise to a plethora of difficulties, principally because the absence of legislation does not mean an absence of surrogacy. Each year, more and more children are born through surrogacy to Irish intended parents, both at home and abroad. They are born, to use the words of O'Donnell $\mathrm{J}$ in $M R$ and An tArd Chláraitheoir, 'into a legal half world' where their status is 'determined by happenstance'. ${ }^{6}$

The absence of specific legislation to regulate surrogacy creates a number of difficulties. Without specific legislation, parentage is determined by recourse to the same rules that apply in 'natural' conception: the woman who gives birth to the child is always regarded as the child's legal mother; if she is married to a man, her husband is presumed to be the legal father; and if she is not married (or if the presumption in favour of the husband is rebutted), the genetic father is recognised as the legal father. Therefore, in cases of surrogacy, the surrogate is always recognised as the legal mother, ${ }^{7}$ and the genetic father typically is recognised as the legal father. This means that an intended mother (genetically related to the child or not), or an intended father who is not genetically related to the child, are not recognised as legal parents upon the birth of the child. They are left to rely on guardianship or adoption as their only options to acquire any legal connection to the child that they will likely raise from birth. ${ }^{8}$

\section{Proposals for regulation}

Ireland has committed itself to introducing legislation to regulate surrogacy and surrogacy legislation has been discussed for many years. As far back as 2005, the Commission on Assisted Human Reproduction recommended by a majority that legislation should be introduced to regulate surrogacy and that the intended parents should be presumed to be the legal parents of any child born through surrogacy. 9 In January 2014, the Irish government included proposals to regulate surrogacy in the Children and Family

3 For example, in California, surrogacy is regulated under the Uniform Parentage Act and Assembly Bill No 1217.

4 In Ireland, for example, surrogacy is legal but there is no specific regulation.

5 In Italy, for example, surrogacy is prohibited under Law No 40 of 19 February 2004 (the Medically Assisted Reproduction Act). This prohibition and its effects were considered by the European Court of Human Rights in Paradiso and Campanelli v Italy, App No 25358/12, 24 January 2017. See: L Bracken, 'Assessing the Best Interests of the Child in Cases of Cross-border Surrogacy: Inconsistency in the Strasbourg approach?’ (2017) 39 Journal of Social Welfare and Family Law 368.

$6 \quad$ MR and An tArd Chláraitheoir [2014] IESC 60; [2014] 3 IR 533, [211].

7 Ibid.

8 For discussion of the unsuitability of guardianship and adoption in this context, see: L Bracken, 'The Role of the Best Interests Principle in Regulating Parentage in Surrogacy in Ireland' [2017] International Family Law 115 .

9 Report of the Commission on Assisted Human Reproduction (Dublin 2005). 
Relationships Bill 2014. In essence, the 2014 Bill made provision for a 'delayed' or 'postbirth' model of parentage whereby the surrogate would be recognised as the legal mother upon the birth of the child ${ }^{10}$ and the intended parents could subsequently apply for a declaration of parentage to extinguish the surrogate's parental status and to acquire parental responsibilities and rights for themselves. ${ }^{11}$ The surrogate's consent would be required before this declaration could be made ${ }^{12}$ and the application for the declaration could be sought not less than 30 days after and not more than six months after the child's birth. ${ }^{13}$

The surrogacy proposals were subsequently removed from the 2014 Bill, as it was felt that further policy work and consultations were required in relation to surrogacy. As such, the regulation of surrogacy was deferred to the recently published Assisted Reproduction Bill 2017. The new General Scheme proposes to introduce a comprehensive framework for the regulation of surrogacy in Ireland. The model of parentage that is proposed is broadly similar to that put forward in the 2014 Bill, but there are some notable differences. For example, the 2017 Bill requires that all surrogacy agreements be preauthorised by a new Assisted Human Reproduction Regulatory Authority, which had not previously been proposed. The main elements of the proposed regulation of surrogacy are set out below.

Head 36 of the General Scheme establishes a number of conditions that have to be met for surrogacy to be permitted. This Head establishes a fairly restrictive model of surrogacy as it only permits specific types of surrogacy arrangements. It establishes that the surrogacy must be domestic, gestational and non-commercial. This means that the proposed regulation will not apply in situations where international or cross-border surrogacy is used and so intended parents who have embarked on surrogacy abroad would not be able to rely on the provisions in the General Scheme to establish their parentage upon return to Ireland. The surrogacy must also be gestational which means that the surrogate must not be genetically related to the child. Thus, 'traditional' surrogacy, where the surrogate provides her egg to enable the conception of the child, is not permitted. Commercial surrogacy is also prohibited meaning that the surrogate cannot be offered or given any payment or other reward for her involvement in the process. ${ }^{14}$ 'Reasonable expenses' are, however, allowed. Reasonable expenses are defined in Head 41 of the General Scheme to include medical expenses, travel expenses, loss of earnings, and legal advice among other things. In fact, it would seem that the surrogate would have the right to demand payment of such expenses as the General Scheme specifically states that a surrogacy agreement is not an enforceable contract, except in relation to the payment of the surrogate's reasonable expenses. ${ }^{15}$

In order to avail of the regulation proposed by the General Scheme, the surrogate and intended parents must also meet specific criteria. The surrogate must: be habitually resident in Ireland; have previously given birth to a child; be least 25 years of age but under 47 years of age; and must have been assessed and approved as suitable to act as a surrogate by a registered medical practitioner and also by a counsellor. ${ }^{16}$ The intending parent(s) must be at least 21 years of age and at least one of them must: be under 47 years of age; be habitually resident in Ireland; and have contributed a gamete to the child's

10 General Scheme of the Children and Family Relationships Bill 2014, Head 12(1).

11 Ibid Head 13

12 The surrogate's consent would be required unless she is deceased or cannot be located: ibid Head 13(9)(b).

13 Ibid Head 13(5).

14 Ibid Head 40.

15 Ibid Head 41.

16 Ibid Head 38. 
conception. Where there is only one intended parent, one of the following conditions must apply: he or she must be unable to gestate a pregnancy; unable to conceive a child for medical reasons; unlikely to survive a pregnancy or giving birth; or likely to have her health significantly affected by a pregnancy or by giving birth. Where there are two intended parents, together as a couple they must either be: unable to gestate a pregnancy; unable to conceive a child for medical reasons; include a woman who is unlikely to survive a pregnancy or giving birth; or include a woman who is likely to have her health significantly affected by a pregnancy or by giving birth. ${ }^{17}$

The Bill also requires that the surrogate and intending parent(s) undergo counselling and receive independent legal advice at each stage of the surrogacy agreement. ${ }^{18}$ The stages referred to are: (i) before the agreement; (ii) after the birth of the child but before the child is living with the intending parents; and (iii) at the time of the application for the transfer of parentage of the child. ${ }^{19}$ In addition, the General Scheme provides that the personal details of each intending parent, the surrogate, donor (where applicable) and any child born under the surrogacy agreement must be recorded in the National Surrogacy Register. ${ }^{20}$

The model of parentage established under the 2017 Bill is broadly similar to that which had been put forward in the 2014 Bill. It is a 'delayed' model of parentage whereby the surrogate will be recognised as the legal mother on the birth of the child (and if she is married to a man, her husband is recognised as the legal father). The intending parents may not automatically have any legal connection to the child at birth. The General Scheme provides that following the birth of the child, the surrogate is required to provide her consent to the child living with the intending parent(s). ${ }^{21}$ Thereafter, the intending parent(s) (or the surrogate) can apply to the court for a parental order to transfer parentage from the surrogate to the intending parent(s). This application cannot be made earlier than six weeks and not more than six months after the child's birth, ${ }^{22}$ and the consent of the surrogate (and her husband, if she has one) is required before the parental order can be granted. This requirement can be waived in certain circumstances, such as where the surrogate is deceased or cannot be located. ${ }^{23}$

A notable difference between the 2017 Bill and the earlier proposals to regulate surrogacy is the requirement for pre-authorisation of the surrogacy agreement. An AHR treatment provider is required to apply to the Regulatory Authority and receive written authorisation for a surrogacy agreement before any treatment can be provided under that agreement. ${ }^{24}$ The Regulatory Authority will only provide authorisation if the agreement meets all of the conditions set out in Head 36 of the Bill and if the agreement has been signed by the surrogate, and each intending parent. Once the authorisation is issued, it is only valid for the period specified in the authorisation, up to a maximum period of two years. The pre-authorisation of the surrogacy agreement does not determine the allocation of parentage in any way. It simply ensures that all of the conditions set out above are adhered to before the conception of the child takes place. After the birth of

17 Ibid Head 39.

18 Ibid Head 43.

19 Explanatory Note accompanying Ibid Head 43.

20 Ibid Ibid Head 36.

21 Ibid.

22 Ibid Head 47.

23 Ibid Head 48.

24 Ibid Head 37. 
the child, the intended parents will still need to make an application to the court for a parental order to transfer parentage to them.

The time limits proposed in the General Scheme for the parental order application also differ significantly from those proposed in the 2014 Bill. Under the 2014 proposals, the application to transfer parentage could not be sought less than 30 days after and not more than six months after the child's birth. ${ }^{25}$ By contrast, the General Scheme proposes that the application for the parental order could not be made earlier than six weeks and not more than six months after the child's birth. ${ }^{26}$ The Explanatory Note accompanying the General Scheme explains that this longer waiting period is designed 'to allow the surrogate sufficient time to recover from the rigours of pregnancy and childbirth before participating in proceedings' ${ }^{27}$ The surrogate's consent is required for the parental order to be granted and so the rationale behind the waiting period is that she must be in full health before consenting to the transfer of parentage.

The rationale for the delay in the transfer of parentage might seem a sensible approach, but a significant difficulty with any sort of time limit for the transfer of parentage is that the chid will be in the care of the intending parents from birth. ${ }^{28}$ As was noted above, at the time of the child's birth, at least one of the intended parents will not be recognised as a legal parent and therefore will not have automatic legal rights and responsibilities towards the child. This leaves the child in a vulnerable position as the intended parents may have limited legal powers to care for the child, for example, in relation to medical decision-making. While this criticism could also be made about the 2014 proposals (and indeed any delayed model of parentage), the shorter waiting period at least reduced the period of vulnerability. Extending the time limit so that the parental order cannot be sought until at least six weeks after the child's birth prolongs the child's precarious legal position.

The time periods proposed under the 2017 General Scheme are the same as those that currently apply in England and Wales under the Human Fertilisation and Embryology Act 2008. Under this Act, the surrogate is automatically regarded as the legal mother upon the birth of a child. The intended parents may then apply for a parental order to transfer legal parentage to them. Similar to the General Scheme, this order cannot be made for the first six weeks after the child's birth, but it must be made within six months of the birth and the surrogate's consent is required for the order to be granted. ${ }^{29}$

It is arguable that the approach adopted in the current English regulation, and mimicked in the General Scheme, disproportionately favours the surrogate at the expense of other stakeholders. The surrogate is effectively given a veto over the transfer of parentage to the intended parents and has the power to change her mind about the transfer at any time up to that point. In England and Wales, the difficulties that arise under this approach are exemplified by recent case law such as in the recent case of $A B$ (Surrogacy: Consent). ${ }^{30}$ In this case, two children born through surrogacy had been in the care of their intended parents (who were also the genetic parents) since the day following their birth. The intended parents subsequently applied for a parental order to transfer

25 General Scheme of the Children and Family Relationships Bill 2014 Head 13(5).

26 General Scheme of the Assisted Human Reproduction Bill 2017, Head 47.

27 Explanatory Note accompanying ibid at p 119.

28 The General Scheme requires the surrogate to provide her consent to the child living with the intended parents following his or her birth: Head 46 of the General Scheme of the Assisted Human Reproduction Bill 2017.

29 Human Fertilisation and Embryology Act 2008, s 54(7) and s 54(11).

30 AB (Surrogacy: Consent) [2016] EWHC 2643 (Fam). 
parentage to them and to extinguish the surrogate's parental status. The parental order could not be granted, however, because the surrogate and her husband ultimately refused to give their consent to the transfer of parentage. This refusal was not based on any desire on the part of the surrogate and her husband to keep the children, nor did they raise any concerns about the suitability of the intended parents. Their refusal was based on 'their own feelings of injustice, rather than what is in the children's best interests'. ${ }^{31}$ Essentially, the surrogate felt that the intended parents did not show sufficient concern for her wellbeing whilst pregnant.

In this case, the intended parents had met the surrogate and her husband through a non-profit organisation. The parties underwent the recommended three month 'getting to know' period and attended for mandatory implications counselling provided by the fertility clinic before the embryo transfer took place. With the exception of the provision of the consent of the respondents, all other legislative criteria for the making of a parental order had been met: gestational surrogacy was used; 32 both of the intended parents were the genetic parents of the children; ${ }^{33}$ the applicants were married; ${ }^{34}$ they applied for the parental order within six months of the children's birth; 35 the children had their home with the applicants since birth; 36 the applicants domicile of origin was England; ${ }^{37}$ the applicants were both over 18 years; ${ }^{38}$ and they had only paid the surrogate reasonable expenses which did not require court authorisation. ${ }^{39}$ Nonetheless, without the consent of the surrogate and her husband, the parental order could not be granted.

The children at the centre of this case are now (still, it seems) left in a position where the surrogate and her husband remain the legal parents but have no desire to play any part in their upbringing. Meanwhile, the children are cared for by the intended parents who are not recognised as legal parents. This is such notwithstanding an acknowledgment by the court that 'the children's lifelong welfare needs require a parental order to be made'. ${ }^{40}$ In the circumstances, the only option available to the Court was to

... express the hope that [the surrogate] will be able to rediscover what led her to undertake such a selfless role and see the situation from the view point of these young children. From the perspective of these children's lifelong emotional and psychological welfare parental orders are the only orders that accurately and properly reflect the children's identity as surrogate born children. ${ }^{41}$

This case highlights the disadvantages inherent in the delayed model of parentage: it leads to uncertainty regarding the child's parental status and it fails to respect the reality of the child's intended upbringing. This leaves the child in a vulnerable position as the intended parents will typically care for the child from birth but may lack any automatic rights and responsibilities in doing so. Even where the surrogacy arrangement is carried out as intended (as most are), the delayed model of parentage ignores the reality of the situation. As Gamble, notes '[w] here the surrogacy arrangement runs according to plan, this works

31 Ibid [8].

32 Human Fertilisation and Embryology Act 2008, s 54(1)(a).

33 Ibid s 54(1)(b).

34 Ibid s 54(2)(a).

35 Ibid s 54(3).

36 Ibid s 54(4)(a).

37 Ibid s 54(4)(b).

38 Ibid s 54(5).

39 Ibid s 54(8).

40 AB (Surrogacy: Consent) (n 30) (Fam) [11].

41 Ibid [32]. 
to everyone's detriment, leaving the parents without any parental responsibilities, the surrogate with responsibilities she does not want, and the child in limbo for far too long. ${ }^{42}$

It should, of course, be noted that the Irish proposals contain a provision that would prevent a case like $A B$ (Surrogacy: Consent) from arising in this jurisdiction if the proposals are signed into law. Head 48 of the General Scheme would allow a court to waive the requirement for consent to be provided by the surrogate or her husband where he or she:

a) is deceased;

b) lacks the capacity to provide consent;

c) cannot be located after reasonable efforts have been made to find him or her; or

d) for any other reason the court considers to be relevant.

The last clause would allow the court to grant the parental order in a case in which the surrogate does not consent, and where there are exceptional reasons to do so. Conceivably, this would apply in a case such as $A B$ (Surrogacy: Consent) where there is seemingly no reasonable basis for the surrogate to refuse her consent and where the best interests of the child require that the parental order is granted.

Notwithstanding this subtle but significant difference between the Irish proposals and the English approach, it is submitted that Ireland should remain wary of the 'delayed' or 'post-birth' model of regulation that is proposed. The delayed model of parentage ignores the reality of most surrogacy arrangements. It has also led to confusion among healthcare professionals in England and Wales, negatively affecting the provision of care to all stakeholders in surrogacy. Recent newspaper reports have revealed that staff at certain hospitals have required surrogates to hand over new-born babies to intended parents in car parks because the hospitals feared that they would be open to liability if the handovers were to take place on their premises. ${ }^{43}$ In other cases, the intended parents have not been allowed to be present for the birth of their child. ${ }^{44}$ These reports demonstrate that, notwithstanding an increase in the use of surrogacy in recent years, hospitals are still unsure how to treat intended parents because, under the delayed model of parentage, those intended parents have no legal relationship with the child at birth.

It is also notable that both intended parents and surrogates have called for reform of the English surrogacy laws in recent years. In a 2015 study published by Surrogacy UK, for example, 70.1 per cent of intended parents who responded indicated that the surrogacy laws in England and Wales are in need of reform, while 65.7 per cent of surrogates expressed the same sentiment. ${ }^{45}$ Of the surrogates who responded to the survey, 64.9 per cent said that they thought that the intended parents should be the legal parents of a child, 'whether genetically related or not', while 68.5 per cent did not believe that the surrogate should have the right to change her mind about giving the baby to the intended parents. ${ }^{46}$

42 Natalie Gamble, 'Should Surrogate Mothers Still Have an Absolute Right to Change their Minds?’ Bionews (22 October 2012) <www.bionews.org.uk/page_196180.asp>.

43 Siobhan Fenton, 'NHS Hospitals Forcing Surrogate Families to Hand over Newborn Babies in Car Parks Due to "Dire and Outdated" Laws' The Independent (London, 29 October 2016) <www.independent.co.uk/news/uk/home-news/nhs-surrogate-births-rules-laws-parents-babies-handedover-car-parks-a 7381646. html $>$.

44 Ibid.

45 Surrogacy UK, Surrogacy in the UK: Myth Busting and Reform: Report of the Surrogacy UK Working Group on Surrogacy Law Reform (Surrogacy UK 2015) 26.

46 Ibid. 
The delayed model of parentage is increasingly regarded as out of step with the reality of surrogacy. England and Wales forged new ground when it introduced its first Act of Parliament to regulate surrogacy, the Surrogacy Arrangements Act 1985, over 30 years ago. This law became a prototype for the regulation of surrogacy in countries around the world and is still in force today (as amended by the HFEA 1990 and HFEA 2008). However, recent developments in England and Wales, discussed above, demonstrate the inadequacy of the English surrogacy laws in contemporary society and suggest that such developments should act as a caution to other countries, including Ireland, yet to introduce legislation to regulate surrogacy.

The proposals in the Irish General Scheme suffer from the same disadvantages as the English regulation discussed above, with the added burden of pre-authorisation. This requirement essentially means that the surrogacy agreement must be approved twice: before conception by the Regulatory Authority and after birth by the courts. A much simpler (and cheaper) process would be to allow for pre-conception court orders that provide approval of the surrogacy arrangement and determine the parentage of the child before conception takes place. This approach would allow the surrogate to give her consent to the transfer of parentage in advance of the conception with the effect that the intended parents acquire full parental responsibilities and rights at birth and the surrogate is never recognised as a legal parent. This approach would also provide certainty, as the parties would know who the child's legal parents are at the outset and there would be no need for post-birth litigation to establish who the legal parents are or indeed should be.

\section{Pre-conception court orders}

Pre-conception court orders allow for a child's legal parental status to be determined prior to conception and so the intended parents are recognised as the child's legal parents at birth. This approach to allocating parentage in surrogacy is adopted in a number of countries, such as in South Africa. In that country, surrogacy agreements must be validated by the High Court before the surrogacy is undertaken. ${ }^{47}$ Where the preconception order is granted, the intended parents are recognised as the legal parents upon the birth of the child ${ }^{48}$ and the surrogate does not acquire any legal parental status. There is an exception for cases of 'partial' or gestational surrogacy where the surrogate is also the genetic mother of the child. In this case, the surrogate retains the right to terminate the surrogate motherhood agreement by filing written notice with the court within 60 days of the birth of the child. ${ }^{49}$

The pre-conception order removes many of the difficulties that can arise under the delayed model of parentage, as discussed above. The pre-conception order allows the intended parents to acquire full joint parental responsibilities and rights from the moment of the child's birth, which offers security and protection to the child. In the South African case of Ex Parte MS and Others, ${ }^{50}$ the court noted that pre-authorisation of a surrogacy agreement is 'aimed largely at ensuring that there is certainty in the legal relationship between the parties involved'. Furthermore: 
[It] advances the principle of the best interests of the child in that there can be no doubt that it is in the prospective child's best interests for his or her legal and parental status to be settled at the earliest possible opportunity. Ideally, this should be before there is any prospect of conception. ${ }^{51}$

It is submitted that the element of certainty emphasised by the Court in Ex Parte MS is one of the main advantages of determining parentage prior to conception. This certainty promotes the best interests of the child as the intended parents have automatic rights and responsibilities towards him or her. It also reflects the practical reality of the situation and the child's intended upbringing. It is to be hoped, therefore, that the proposals contained in the 2017 General Scheme will be amended to allow for pre-conception agreements to be adopted to not only authorise the surrogacy arrangement in advance but to also determine the parentage of the child before treatment takes place.

\section{Conclusion}

Ireland has a long-established tradition of looking across the Irish Sea for inspiration in legislative matters. Quite often, this approach allows the Irish legislature to produce innovative laws that fit the needs of contemporary society. This article has shown, however, that the surrogacy laws of England and Wales should not be subject to the same treatment and should not be adopted in any future Irish legislation in this area. Recent developments in England and Wales demonstrate that the English surrogacy laws are out of step with the reality of surrogacy in that country and show that the delayed model of parentage is not an appropriate one for Ireland to follow. In this light, it has been shown that the model of parentage advanced in the 2017 General Scheme would not be appropriate and should be reconsidered by the legislature. In order to fully protect the best interests of children who are born through surrogacy, it is argued that an intentionbased model of parentage, based on a system of pre-conception agreements that allow parentage to be determined before conception, should be introduced. 
